\title{
Sociedad y oficialismo: la crispación del discurso oficial sobre sexualidad del Ministerio de Educación Pública, Costa Rica, 1960-2011
}

Society and Official Mainstream: Tensions on the Ministry of Public Education Official Discourse on Sexuality Costa Rica, 1960-2011

Sociedade e oficialismo: A tensão no discurso oficial sobre a sexualidade de Ministério da Educação Pública Costa Rica, 1960-2011

\author{
Hermes Campos-Monge \\ Escuela de Historia \\ Universidad Nacional, Costa Rica \\ Recibido: 10/5/2020 - Aceptado: 18/06/2020
}

La segunda mitad del siglo XX y principios del siglo XXI se caracterizó por grandes cuestionamientos a los discursos imperantes en torno a la educación sexual. Un desafío contra el poder político imperante y los convencionalismos del orden moral, en la sociedad costarricense en el período 1960-2018. La participación de actores sociales como la Iglesia Católica, sociedad civil, instituciones públicas y organizaciones no gubernamentales (algunas con voces contestatarias), representantes de discursos hegemónicos y contra hegemónicos, provocaron grietas en la educa-

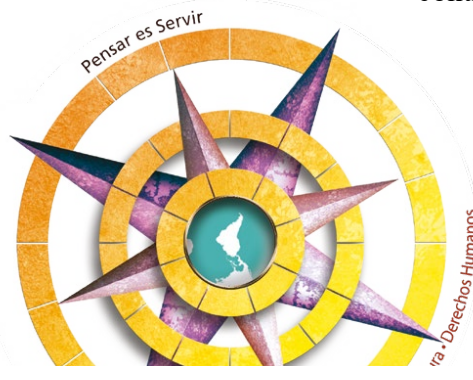
ción media, que permitieron proponer y elaborar programas sobre educación sexual para ser ejecutados por el Ministerio de Educación Pública. No obstante, estas voces de estos actores sociales, no siempre son escuchadas e incorporadas en los discursos 
oficiales por quienes detentan el poder, ya que no se ajustan a los intereses de la clase dominante.

Palabras clave: Sexualidad, corporalidad, poder, discurso, programas de educación sexual

\begin{abstract}
The second half of the 20th century and the beginning of the 21 st century was characterized by major challenges facing the prevailing discourses on sex education. A challenge against the prevailing political power and the conventions of the moral order was witnessed in Costa Rican society in the period 1960-2018. The participation of social actors such as the Catholic Church, civil society, public institutions and non-governmental organizations (some with contentious voices), representatives of hegemonic and counter-hegemonic discourses, led to cracks in secondary education, which made it possible to propose and develop new programs on sex education to be implemented by the Ministry of Public Education. However, the voices of these social actors are not always heard and incorporated into official discourses by those in power, since they do not meet the interests of the ruling class.
\end{abstract}

Keywords: Sexuality, corporeality, power, discourse, sex education programs, Costa Rican education, Temas of Our America

\title{
Resumo
}

A segunda metade do século XX e o início do século XXI foi caracterizada pelos grandes desafios enfrentados pelos discursos predominantes sobre educação sexual. Um desafio contra o poder político prevalecente e as convenções da ordem moral foi testemunhado na sociedade costarriquenha no período 19602018. A participação de atores sociais como a Igreja Católica, a sociedade civil, instituições públicas e organizações não-governamentais (algumas com vozes controversas), representantes dos discursos hegemônicos e contra-hegemôni$\cos$, levou a rachaduras no ensino secundário, o que possibilitou propor e desenvolver novos programas de educação sexual a serem implementados pelo Ministério da Educação Pública. Entretanto, as vozes destes atores sociais nem sempre são ouvidas e incorporadas aos discursos oficiais pelos detentores do poder, uma vez que não atendem aos interesses da classe dominante.

Palavras chave: Sexualidade, corporeidade, poder, discurso, programas de educação sexual, educação costa-riquenha, Temas de Nossa América

62 Sociedad y oficialismo: la crispación del discurso oficial sobre sexualidad del Ministerio de Educación Pública, Costa Rica, 1960-2011

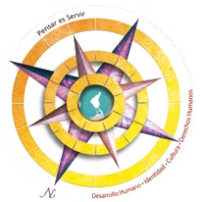


La historia de la sexualidad en Costa Rica inicia desde finales del siglo XIX, dada la preocupación del sector educativo sobre la higiene sexual (enfocada en la prevención del contagio de enfermedades venéreas), pues si se considera el contexto de la sociedad costarricense, aunque se presentó desde un enfoque médico, fue quizá la opción menos antagónica para iniciar. A partir de 1926, en la Escuela Normal y el Colegio Superior de Señoritas ya se incorporaba la educación sexual mediante un curso llamado: Puericultura y Ginecología (Molina Jiménez, 2019, p. 4). Este fue un impulso muy importante en la educación sexual, no solo por su incorporación a la instrucción pública, sino por la ruptura de una educación orientada a los varones y el posicionamiento de las mujeres dentro de esos espacios oficiales.

La sexualidad se comenzó a incorporar en la instrucción pública formalmente en 1929, cuando el ministro de Educación, Luis Dobles Segreda, elaboró el reglamento para la segunda enseñanza, donde se determinó la necesidad de disponer de los servicios médicos para proporcionar conferencias sobre higiene, funciones sexuales y venerismo, principalmente a los varones (Molina Jiménez, 2019). La educación sexual en el período 1920 hasta 1960 , se caracterizó por la prevalencia de un enfoque eugenésico1 y la intensificación de los valores y roles tradicionales del género; no solo por la "monopolización inicial de la educación sexual enfocada en los varones" (Molina Jiménez, 2019, p. 1), sino por la invisibilización oficial de la sexualidad femenina desligada de la maternidad.

Aunque los primeros esfuerzos en materia de sexualidad en Costa Rica datan de 1920, no fue sino hasta 16 de mayo de 1969 cuando se plasmó, ante el Consejo Superior de Educación, la creación del Programa de Adiestramiento en Educación Sexual y, en 1970, el establecimiento de la Asesoría de Educación Sexual y Planificación Familiar, que responden a los intereses propios de esta investigación, que aborda el periodo de 1960 hasta el 2018, caracterizado por un continuo cuestionamiento a las estructuras de poder que pretender sostener el status quo de la sexualidad tradicional.

1 "Entendida como las teorías o prácticas dirigidas al perfeccionamiento biológico de la especie humana. Esta teoría comenzó a atraer la atención de intelectuales y políticos costarricenses desde finales del siglo XIX; aunque se desarrolló en Estados Unidos y Europa a finales del siglo XIX e inicios del siglo XX, para prevenir las enfermedades venéreas en hombres y promover un mejor desempeño maternal femenino" (Molina, 2019: p. 2) 
Desde finales de los años cincuenta, en el Estado costarricense se vislumbraban ideas sobre la necesidad de tener un programa sobre sexualidad; pero preocupaba qué contenidos enseñar, quién los abordaría y cuándo daría inicio el programa. Para 1959 el periódico La República (Ranucci, 1959), publica una entrevista con una funcionaria del Ministerio de Educación, quien reconoce la necesidad de educar en sexualidad y la existencia de un proyecto de reforma para crear un plan sobre sexualidad en el Programa de Ciencias. No obstante, esta reforma nunca salió a la luz pública, lo que sugiere que nunca se aprobó, ya que no hubo rastros en los periódicos de la época ni en otras fuentes documentales.

Las propuestas de la Revolución Cultural, a inicios de los sesentas, se replantearon los discursos imperantes sobre la sexualidad, principalmente en aquellas instituciones sociales reconocidas por antonomasia para educar. La primera institución desafiada fue la familia y el hogar, porque representaban el principal dispositivo de control de poder $\mathrm{y}$ socialización, donde se determinan aspectos de la vida cotidiana en relación con: cómo se deben asumir las relaciones sexuales, la procreación, la crianza de los niños y las niñas, la socialización, la supervivencia y la transmisión de recursos económicos a sus miembros (Bloch, 2013).

El bono demográfico fue un elemento importante de la década de los sesentas, pues buscaba que la población aumentara la tasa de nacimientos, posiblemente debido a las proyecciones de envejecimiento y los descensos en las tasas de natalidad (Brenes Camacho, 2014). Aunque no se encontró evidencia para sustentar este argumento, fue posible que al incrementar la tasa de nacimientos y considerando el acceso limitado a la educación sexual, los sectores más pobres y vulnerables engrosaron mayormente las tasas de natalidad. El control de natalidad, hasta este momento, no fue considerado dentro de lo poco que se pudo conocer sobre la sexualidad, porque las políticas de salud y educación en materia de sexualidad estaban enfocadas en la prevención de enfermedades de transmisión sexual, aunque su implementación quedó en tela de juicio, ya que se menciona cómo los casos de sífilis crecieron en 1960:
Al iniciar el año de 1960 hemos vuelto a llegar a la certidumbre de que la ausencia de la educación sexual en el país, es la causa di- recta del crecimiento y arraigo de las enfermedades venéreas, y del aniquilamiento físico y psíquico de las nuevas generaciones. Ese

64 Sociedad y oficialismo: la crispación del discurso oficial sobre sexualidad del Ministerio de Educación Pública, Costa Rica, 1960-2011 Hermes Campos-Monge

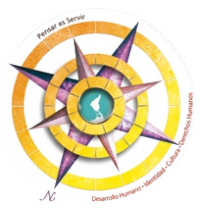


aumento en las estadísticas por sífilis, bastante revelador del resultado de una política de hipocresías sanitarias, para llamar las cosas de alguna manera, es quien debe ponernos hoy una vez más en actitud de alerta, para impedir que el mal siga echando raíces en nuestra patria... (Monestel Arce, 1960, p. 2)

La preocupación sobre el venerismo en Costa Rica pudo ser causante de que durante la celebración de $\mathrm{La}$ Conferencia Nacional de Enseñanza Media, que tuvo lugar en San José del 26 al 31 de agosto de 1963, auspiciada por el Ministerio de Educación Pública y la Universidad de Costa Rica, se haya dispuesto brindar una educación sexual a jóvenes que promoviera prácticas sexuales moralmente aceptables, es decir, las que se ejecutan dentro del matrimonio y para el matrimonio, desde una lógica heterosexual, como se expresa en el siguiente enunciado:

Dar a los jóvenes instrucción oportuna aprovechando todos aquellos estudios y disciplinas, tales como Biología, Sociología, Psicología, etc., considerando que la psicopatología de los conflictos matrimoniales es causada en gran parte por la impreparación de los cónyuges. (MEP, 1964, p. 40)

De acuerdo con el texto anterior, las preocupaciones por las enfermedades de transmisión sexual impidieron comprender que el verdadero problema fue lo limitado del conocimiento sobre la sexualidad y el cuerpo en la juventud, pues la restricción de los deseos sexuales durante la adolescencia no puede evitarse. Pero como lo explica Bauman (2011), "es necesario inhabilitar esos impulsos, categorizándolos como problemas de seguridad, para deshumanizarlos" (p. 60), porque una sexualidad no controlada amenaza la seguridad moral.

Para finales de los años sesenta y principios de los setenta, el Ministerio de Educación Pública creó, por decreto ejecutivo n. ${ }^{\circ} 26$ del 18 de marzo de 1970, la Asesoría de Educación Sexual y Planificación Familiar (La Nación, 1971). Este organismo técnico es el resultado de una política pública que, enfocada en el control de los cuerpos, determinó los lineamientos oficiales para definir cómo se debe entender y enseñar en materia de sexualidad. No obstante, estas políticas no son casuales, son de vigilancia y su impacto dependerá de la docilidad y utilidad en la significancia de los cuerpos, como lo menciona Foucault (2003, p. 83):

La modalidad, en fin: implica una coerción ininterrumpida, constante, que vela sobre los procesos de la actividad más que sobre su resultado y se ejerce según una 
codificación que retícula con la mayor aproximación el tiempo, el espacio y los movimientos. A estos métodos que permiten el control minucioso de las operaciones del cuerpo, que garantizan la sujeción constante de sus fuerzas y les imponen una relación de docilidad-utilidad, es a lo que se puede llamar las "disciplinas".

De acuerdo con lo anterior, el cuerpo se convierte un objeto que debe ser conquistado por estos mecanismos disciplinarios y sometidos a vigilancia, porque no existe capacidad individual (cada persona) para cuidarlo. El cuerpo es visto como un promotor de males sociales que deben de ser oprimidos o exterminados (cuando no se logra curar) y debe cumplir las funciones establecidas por dispositivos de control, porque está al servicio de "otro" y la forma de asegurarlo es la vigilancia de la sociedad, porque es protectora del orden natural. Estos lugares desde donde se marcan las diferencias para clasificar a quienes no son "normales", es decir, "los otros", son producto de lo que Lorite (1995) ha denominado el orden:

El orden es la diferenciación: una canalización absorbente de los espacios del desorden, que hace que la sociedad se divida, se segmente, se jerarquiza, se pliega marcando la topografía de un orden en sus pensamientos, sus cuerpos, sus lenguajes, sus ornamentos, sus territorios. Se trata de diferencias internas indispensables para el sistema en la medida en que articulan su constitución y el despliegue de sus posibles activadores del orden en cuanto núcleo de potencial desorden: masculino/femenino; niños/jóvenes/adultos/ancianos; profano/sagrado; público/privado; permitido/prohibido. (p. 6)

Los primeros discursos sobre sexualidad estuvieron ligados a la familia y al sistema educativo (directa o indirectamente) que enseñaba la sexualidad a favor del matrimonio. Aunque no se poseía un programa exclusivo sobre sexualidad, se entrevé una narrativa relacionada con las corporalidades, la modalización y el comportamiento, que deben asumir los hombres y las mujeres, según las normas culturales que la sociedad reconoce como válidas y aceptables. Por ejemplo, en 1971 se inauguró un seminario de sexualidad que expuso:

Hasta el presente año, dos asignaturas: Economía doméstica y Labores Manuales, pretenden cumplir con la difícil y compleja tarea para preparar a nuestras adolescentes, como miembros eficientes de la familia y la comunidad a la que pertenecen. Esa formación para la vida familiar y social, no puede resolverse teniendo solo a los aspectos de "enseñar a cocer,

66 Sociedad y oficialismo: la crispación del discurso oficial sobre sexualidad del Ministerio de Educación Pública, Costa Rica, 1960-2011 Hermes Campos-Monge

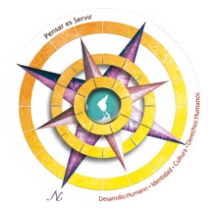


a cocinar y a otras labores manuales", finalidades que persiguen esas áreas en la actualidad. (MEP, 1965, p. 1)

Los aspectos de la vida familiar y comunitaria, según el planteamiento anterior, requieren la indispensable presencia de las mujeres, donde la posibilidad de cambiar su destino es limitada, porque la sociedad como el sistema educativo, le enseñan lo que debe hacer, de acuerdo con su condición de sexo (biológico) y género (cómo debe de ser).

Las representaciones en torno a cómo se construyen y deconstruyen las relaciones de género y las conductas sobre sexualidad corresponden a atribuciones y responsabilidades impuestas y condicionadas al sexo biológico. Además, están vinculadas a la asignación de labores que deben de ser asumidas como hábitos deseables del individuo, para preparar su incorporación a una vida familiar y social, tal como lo establece la siguiente cita:

El realce del nivel moral de la humanidad se está operando en todos los sentidos, pero antes de llegar a esa meta es preciso resolver muy importantes problemas entre ellos: el de la educación de la niña de hoy y la madre del mañana, ya que el destino de la raza humano descansa en la madre. (MEP, 1965, p. 3)
Los aspectos cotidianos identificados en el texto anterior son elementos que se suman en la consigna "lo personal es político", que comienza a erguir un panorama discursivo muy claro para las mujeres; no solo por las prerrogativas de su sexo y el hogar, sino que condiciona el bienestar de la familia y la sociedad en general, al imponerse una categoría como natural y obligatoria sobre temas como: la salud pública, la higiene, la educación, el trabajo de la niñez y todas las condiciones del anhelado bienestar social.

Las pinceladas sobre la sexualidad se comenzaron a vislumbrar en la educación costarricense, en temáticas enfocadas hacia la maternidad, la vida matrimonial, el cuido de familiares, la planificación familiar, la vida conyugal y el cuidado de los niños y las niñas; funciones que son otorgadas a las mujeres, sin posibilidad de decidir y objetar sobre sus deseos, porque a consecuencia de sus características sexuales, la sociedad habló por ellas. De acuerdo con el siguiente texto se pueden identificar los elementos mencionados:

...La integración de importantes contenidos de materia cultural, tomadas de distintos ramos que, organizados de acuerdo con el espíritu de la asignatura, tiendan a dar a la alumna esa formación 
completa y necesaria para que pueda resolver sus problemas del presente, y participar con eficiencia en el hogar y en el seno de la comunidad. (MEP, 1965, p. 2)

El rol de las mujeres en la sociedad es diseñado por un tipo de orden natural que se instituye en el género como categoría de análisis y es amparado por condicionamientos de la cultura, que determinan y reglamentan la forma y significado de los cuerpos de las mujeres, de manera implícita. Se puede interpretar un discurso asociado a la sexualidad, porque se involucran aspectos de su vida cotidiana como la división sexual del trabajo, que se vuelven dispositivos de control donde se construye y define lo permitido para las mujeres y lo prohibido para los hombres y viceversa (Bourdieu, 2000). Estas regulaciones originan la diferencia sexual y determinan las posibilidades de acceder a determinadas prácticas y significados asociados a lo masculino o femenino (Preciado, 2002).

A finales de la década de los sesenta, el 16 de mayo de 1969, se plasmó el primer esfuerzo oficial ante el Consejo Superior de Educación para crear el Programa de Adiestramiento en Educación Sexual y para 1970 se constituye, por decreto ejecutivo, la Asesoría de Educación Sexual y Planificación Familiar. El objetivo de la Asesoría, según se cita, era la de "ser un organismo técnico del Ministerio, era el encargado de tutelar los valores de la familia costarricense como institución y la afirmación de una vida familiar digna según las tradiciones cristianas" (La Nación, 1974 , p. 32A).

La existencia de una instancia técnica oficial del Estado, que solo representa los valores de la familia cristiana, plantea que cualquier otra forma de composición familiar existe en la sociedad, pero no es de la sociedad, porque la norma solo valida la familia cristiana. Sobre esto Bourdieu (2000) plantea:

El sistema mítico ritual desempeña aquí un papel equivalente al que incumbe al orden jurídico en las sociedades diferenciadas: en la medida que los principios de visión y de división que proponen están tan objetivamente ajustados a las divisiones preexistentes, consagra el orden establecido, llevándolo a la existencia conocida y reconocida como oficial. (pp. 20-21)

Los primeros esfuerzos para abordar esta necesidad se convirtieron en dispositivos de control social y corporal, porque el comportamiento de los individuos estaba condicionado (lo explica muy bien el objetivo del programa) a representar los valores tradicionales

68 Sociedad y oficialismo: la crispación del discurso oficial sobre sexualidad del Ministerio de Educación Pública, Costa Rica, 1960-2011

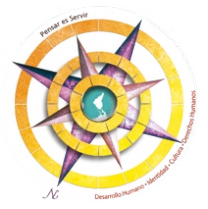


cristianos. El Estado asumió su compromiso con la creación de un programa sobre sexualidad, que parecía ser novedoso, pero que no lo fue, porque en principio perpetuaba los valores propios de los sectores dominantes y mantuvo un profundo interés por someter, por la fuerza, a quienes son desobedientes al poder.

Este programa fue el resultado de la lucha por los derechos humanos de segunda generación, constituidos por los derechos sociales, económicos y culturales, que son una obligación de hacer del Estado; pero también respondió a una realidad de la sociedad costarricense relacionada con los baby boomers de la década de 1960, donde se privilegió el aumento de la natalidad sin control y sin considerar las posibilidades económicas de la sociedad. Por lo tanto, fue necesario establecer acciones sistemáticas para lograr que las personas se reprodujeran de forma controlada y responsable. Sin embargo, esa no fue la posición oficial que asumió el MEP, dado que podría generar descontento social y eso fue lo que ocurrió. En la prensa nacional se publicaron artículos, editoriales y notas en contra de los nuevos programas señalándolos de antinatalistas e invasores de la privacidad familiar.
A pocos años de iniciar el programa, en 1974, se le tildó de antinatalista porque se interpretaba como una intromisión a la intimidad familiar. Establecer políticas de reproducción humana fue asumido como una "invasión por parte del Estado hacia lo interno de las familias y hogares" (La Nación, 1974, p. 32).

Si la premisa de las políticas sobre educación sexual era responder a los valores tradicionales cristianos, el uso de anticonceptivos y de planificación familiar representaba un desafío y un replanteamiento indirecto de la sexualidad más allá de lo reproductivo, para incorporar el tema del placer. Además, se consideraba una invitación al amor libre y a la descomposición moral, como se muestra en la siguiente noticia periodística:

...Porque ese programa no solo no respeta la inviolabilidad de la integridad física y biológica de la persona humana, que es uno de los más esenciales derechos humanos protegidos por las leyes positivas de las naciones civilizadas, sino que haciendo todo lo contrario, estimula y ejecuta la esterilización de mujeres fértiles. Sobre estas prácticas infrahumanas y otras violaciones de derechos fundamentales que nos recuerdan los abortos con bombas compresoras de la Rusia de Lenin y el racismo 
de Hitler y la ola de crímenes. ( $L a$ Nación, 1974, p. 8A).

¿Por qué son los hombres los que hablan con derecho sobre el cuerpo de las mujeres? La participación de las mujeres en las discusiones de la reproducción está ausente, porque no tienen voz, aunque aparezcan como sujetos en la historia. El cuerpo y las regulaciones de la población constituyen los polos sobre los cuales se organiza el poder de la vida, es decir, como lo biológico se refleja en lo político (Osorio, 2012, p. 87). Los procesos biológicos como los nacimientos, la mortalidad, el nivel de salud y la duración de la vida, son problemas tomados como intervenciones y controles reguladores que originan la biopolítica o control de la vida en la población.

Las diferencias dicotómicas asignadas a los hombres y las mujeres, plantea Alda Facio, no se justifican en un elemento biológico, sino social a través de la categoría de género; "porque lo determinante en la identidad sexual es el hecho de ser socializada/o desde el nacimiento o antes como perteneciente a uno u otro sexo" (Facio y Fries, 2005, p. 269). La marginación sobre las mujeres y su consideración como inferiores respecto de los hombres, dice Facio, no tiene un fundamento biológico, sino que la sociedad misma es la que dictamina esas exagerada diferencias biológicas que construyen desigualdades. Sin embargo, estas construcciones sociales no están aisladas de las categorías sociales de raza, etnia, clase socioeconómica, orientación sexual, edad y nacionalidad, entre otras, por lo tanto, plantea Facio (2005):

La sociedad no construye a todas más mujeres idénticamente subordinadas ni a todos los hombres con los mismos privilegios, aunque sí en su universalidad las mujeres son subordinadas por los hombres. Es difícil reconocer que la mujer de clase alta, en edad reproductiva, adinerada, sin discapacidades visibles, blanca y esposa de un banquero, pueda partir de la subordinación de género que una mujer pobre, vieja, discapacitada, lesbiana y negra. (pp. 270-271)

El orden natural, social y cultural comenzó a socavarse, porque colocar en perspectiva oficial el tema de la sexualidad desafiaba la estructura familiar por la incorporación del control de natalidad, el cual generaría anticuerpos que se traducen en crispaciones en la sociedad como a lo interno de la administración educativa. El Estado costarricense, como respuesta desarrolló un programa de capacitación sobre sexualidad para

70 Sociedad y oficialismo: la crispación del discurso oficial sobre sexualidad del Ministerio de Educación Pública, Costa Rica, 1960-2011

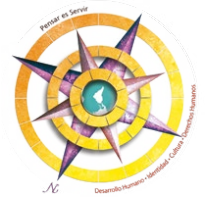


el personal educativo de: Ciencias, Religión, Vida Familiar (Educación para el Hogar), Psicología y Orientación el cual establece que el Estado legitima su discurso:

Estos programas y seminarios se llevan a cabo a tenor de las políticas, programas y planes aprobados por el Consejo Superior de Educación el 16 de mayo de 1969 (acta número 56-69) y decreto ejecutivo que creó la Asesoría de Educación Sexual y Planificación Familiar. (La Nación, 1971, p. 47)

Oficialmente, la educación para la sexualidad que llegaba a las aulas se limitaba a establecer y definir el cuerpo humano desde una perspectiva fisiológica y biológica, empleando ejemplos de animales para explicar la función de la reproducción. La visión sobre la sexualidad desde este enfoque está ligada al concepto de naturaleza, es decir, un hecho incuestionable sobre sí mismo y reconocido por la cultura como aceptable. Además, utiliza el axioma de la reproducción para determinar que el cuerpo ( $\sin$ posibilidad de placer por sí mismo) tiene como fin reproducirse y por eso solo es aceptado entre personas de sexo opuesto.

En esta perspectiva sobre la sexualidad y la forma en la que se concibe el cuerpo, Bourdieu (2000) plantea que "la división de los sexos parece estar en el orden de las cosas, para referirse a lo que es normal y natural, pero hasta el punto de ser inevitable" (p. 21), porque se modaliza (es decir, se atribuye características, actitudes, aptitudes) define y sexualiza los cuerpos (bajo sistema sexo-género) en los diferentes espacios de la vida pública como privada. La Tabla 1 explica cómo se impregna esta visión en la educación.

sexual en el matrimonio a la vista de la procreación - mutua ayuda- remedio de la concupiscencia. (Malavassi, 1979, p. 15A)

El inicio de los años ochenta estuvo marcado por varios escenarios que continuaban desafiando el orden de "normalidad": cuestionamientos a las prácticas identitarias y las representaciones sobre la sexualidad, donde la sociedad costarricense no estaba ajena a ello. En los ochenta, el modelo de sexualidad estaba basado en la reproducción desde la heterosexualidad, pero se comenzaba a fragmentar a consecuencia de las interrogantes sobre las políticas sexuales e identitaria emergidas desde los movimientos homosexuales.

Para 1985, en el marco de las interrogantes a los simbolismos sobre la sexualidad, Costa Rica firma un 


\section{Tabla 1. Contenidos asociados a la sexualidad en el Programa de Ciencias 1979}

\begin{tabular}{lll}
\hline Objetivo & Contenido & Actividades \\
\hline $\begin{array}{l}\text { Explicar la función de } \\
\text { la reproducción. }\end{array}$ & $\begin{array}{l}\text { Las especies que se } \\
\text { perpetúan por medio } \\
\text { de la reproducción }\end{array}$ & $\begin{array}{l}\text { Comente la importancia de la } \\
\text { reproducción de los seres vivos. }\end{array}$ \\
$\begin{array}{l}\text { Diferenciar la repro- } \\
\text { ducción sexual de la } \\
\text { asexual }\end{array}$ & $\begin{array}{l}\text { Los organismos } \\
\text { se reproducen } \\
\text { sexualmente y } \\
\text { asexualmente. }\end{array}$ & $\begin{array}{l}\text { Investigue los diferentes tipos de } \\
\text { reproducción. De ejemplos. }\end{array}$ \\
& $\begin{array}{l}\text { Investigue sobre los diferentes } \\
\text { tipos de reproducción animal y } \\
\text { reproducción vegetal. }\end{array}$ \\
$\begin{array}{l}\text { Diferenciar la fecunda- } \\
\text { ción interna y externa. }\end{array}$ & $\begin{array}{l}\text { La fecundación es la } \\
\text { unión de gametos. }\end{array}$ & $\begin{array}{l}\text { Dé ejemplos de organismos de } \\
\text { reproducción interna y externa. }\end{array}$ \\
\hline
\end{tabular}

Nota: Información tomada del Programa de Ciencias de 1979, tercer ciclo del Ministerio de Educación Pública de Costa Rica. (MEP, 1979, p. 56).

La reproducción es valorada como un fenómeno de consecuencias negativas (en tanto se establezca el placer) que genera imaginarios simbólicos cuando lo personal se convierte en un espacio de disputa, al transformarse este hecho biológico en un asunto político. El cuerpo se convierte en un "dispositivo de control" (Foucault, 2003, p. 104) que debe responder a la reproducción de la especie. Sin embargo, esta idea fue cuestionada por las feministas y los movimientos de liberación homosexual (que ya estaban en su máxima expresión a finales de los setenta y principios de los ochenta), quienes disputaron que el acto coital sea exclusivamente la única finalidad y función del cuerpo. Es en este momento donde emerge el tema del placer, como se aprecia en el siguiente enunciado:

A diferencia del animal, cuya actividad sexual está del todo en todo regulado por las leyes del organismo (régimen hormonal de las hembras) y nada tiene que ver con la libertad y mortalidad, en el hombre, en cambio su dimensión sexual es tarea que entra en la responsabilidad propia de la formación. No puede el hombre entregarse al impulso espontáneo sin graves consecuencias. Debe buscar el recto orden de la actividad

72 Sociedad y oficialismo: la crispación del discurso oficial sobre sexualidad del Ministerio de Educación Pública, Costa Rica, 1960-2011

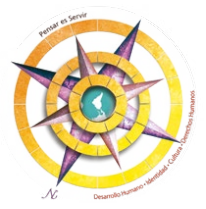


acuerdo de proyecto con el Fondo de Naciones Unidas para Actividades de Población, cuyo objetivo fue incorporar temas de educación en población en tercer ciclo del sistema formal de instrucción. Parte de los compromisos del Ministerio de Educación fue la creación de una oficina en el Centro Nacional de Didáctica. La estrategia del proyecto se basó en el diseño de materiales para distribución al personal docente mediante sesiones técnicas. Se partía de que eran suficientes para apropiarse de la educación sexual y administrar sus contenidos en las aulas (MEP, 1985, p. 3). La Oficina de Educación en Población del MEP estaba encargada de capacitar y sensibilizar en el tema a docentes, como se muestra en la siguiente cita:

...lo que se encargaban era de capacitar y sensibilizar en la temática de desarrollo poblacional, por eso era que se habla de temas de sexualidad, específicamente demografía. Entonces se trabajaba anticoncepción y un poquito de infecciones de transmisión sexual. Ese es como el primer antecedente. (Comunicación personal, Cartín, 2019)

Las primeras Guías sobre sexualidad desde 1985-1999 para tercer ciclo, de acuerdo con Cartín (Comunicación personal, 2019), fueron elaborados en conjunto con la Conferencia Episcopal. Esta documentación estada dirigida específicamente a personal docente, quien posteriormente sería el ente mediador en las aulas. La parcialidad de las guías y del Estado estaba en discusión y surge la pregunta: ¿Quién gobierna qué? Las propuestas para una sexualidad imparcial se revisten con visiones morales y valores hegemónicos.

La familia, la formación moral o religiosa, la sociedad, sus costumbres y tradiciones también imponen límites. Yo no puedo andar desnudo por la calle, porque en nuestra sociedad es contra la ley; mis padres no me permiten hacer ciertas cosas, etc. Si sabemos que querer no siempre es poder y si la libertad no significa hacer solo lo que quiero ¿Qué es la libertad? (MEP, 1985, p. 10)

Esta discusión propone, en algún sentido, definir la libertad de las personas basadas en el límite, aunque se manifiesta una crítica cautelosa sobre quiénes imponen parámetros de conducta, se continúan estableciendo códigos y contenidos desde un discurso de privilegio y de obligatoriedad, porque no existe el espacio para un replanteamiento de las nociones de la libertad sin que pueda ser catalogado como desafiante del sistema y del orden. 
Es necesario reconocer que estas iniciativas se continuaron hasta finales de los noventa, aunque sin éxito alguno dentro del sistema educativo. Pero se considera que uno de los aportes principales de estas guías fue replantear el enfoque de sexualidad más allá de las concepciones biológicas y fisiológicas, avizorando otras cuestiones que involucran el género. Este nuevo paradigma define la sexualidad como:

La forma en la que se expresa la condición sexuada de los varones y mujeres dentro de una sociedad y una cultura particular. La base biológica de la sexualidad es el sexo, es decir, las particularidades anatómicas y fisiológicas que distinguen a varones y mujeres. Los rasgos que definen el comportamiento del varón o de la mujer son expresiones del concepto que cada sociedad tiene de lo que es ser el varón y ser mujer. La sexualidad, por este motivo es aprendida y, como tal, puede ser modificada. Así los comportamientos de varón y ser mujer. (MEP, 1985, p. 15)

La noción de utilizar la reproducción para abordar la sexualidad parece ser desplazada o, por lo menos, hay una lectura que parece estar enmarcada en los nuevos paradigmas que pregonan los movimientos sociales $\mathrm{y}$ la revolución cultural. Aunque se apela al sexo como elemento que nombra a los cuerpos de los sujetos, se entiende, al menos teóricamente, que los rasgos que distinguen a hombres y mujeres son representaciones simbólicas creadas por la cultura y la sociedad. Por lo tanto, se puede deconstruir y romper la indiferencia sobre la existencia de estereotipos masculinos y femeninos.

Los registros simbólicos, "es decir, el registro al que pertenece todo aquello capaz de tener efectos de significación. [sic] No solo el lenguaje y la palabra, sino cualquier cosa capaz de significar pueden ser considerados como significantes" (Conde Soto, 2017, p. 11); son otra fuente importante para entender por qué los imaginarios sobre la sexualidad se mantienen como están, y por qué, a pesar de los cuestionamientos de los movimientos sociales, los contenidos encontrados fuera de la instrucción pública -como la televisión, el cine, la prensa, las revistas y algunos libros de texto- reforzaban los planteamientos dicotómicos del sistema sexo-género que pregonan las sociedades patriarcales. No fue suficiente con los programas para la sexualidad, también fue necesario luchar contra esos otros registros simbólicos que reforzaban el orden moral hegemónico fuera de los límites de la educación oficial y formal (MEP, 1985). De acuerdo con la siguiente figura, se pueden identificar diferentes elementos asociados a la sexualidad:

74 Sociedad y oficialismo: la crispación del discurso oficial sobre sexualidad del Ministerio de Educación Pública, Costa Rica, 1960-2011

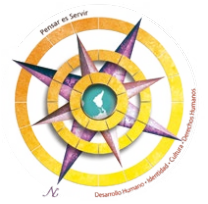




\section{Figura 1. Discursos asociados a la sexualidad 1985}

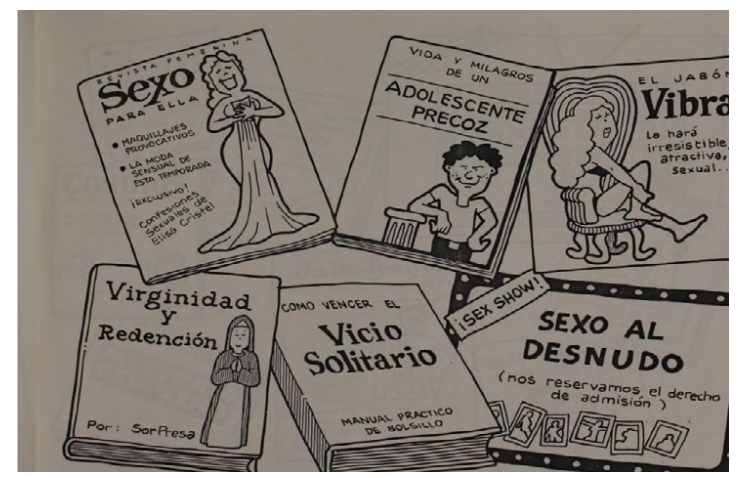

Nota: Tomado de Proyecto Educación en Población -Costa Rica-: Guía didáctica de sexualidad humana y vida familiar $7^{\circ} 1985$.

Estas representaciones asociadas con la sexualidad dentro de la educación y fuera de esta es lo que Van Dijk (1999) define como discurso, porque está asociado con la reproducción del poder social, es decir:

Una habilidad que presupone un poder básico consistente en el acceso privilegiado a recursos sociales escasos, como la fuerza, el dinero, el estatus, la fama, el conocimiento, la información, la "cultura", o incluso variadas formas del discurso público y de la comunicación. (p. 26)

Estos discursos sobre la sexualidad no fue sino hasta 1985 cuando comenzaron a visualizarse dentro de la educación, porque también han sido espacios de significado y de interacción social por las implicaciones del discurso tanto individual como colectivo, es decir, "representaciones que son compartidas por un grupo o una cultura, como el conocimiento, las actitudes y las ideologías" (Van Dijk, 1999). Estas ideas, a mediados de los ochenta y durante toda la década de los noventa y los primeros decenios del siglo XXI, serán los canales donde se desafía, consolidadamente, una lucha y crispación social entre quienes apoyan la reproducción de los paradigmas tradicionales sobre la sexualidad y quienes apelan a la deconstrucción y relectura de las nuevas identidades e interpretaciones sobre la sexualidad.

A finales de los años ochenta, el arremetimiento de los sectores más 
conservadores de la sociedad costarricense comenzó a tener una mayor participación en el escenario nacional, como consecuencia de las ideas planteadas sobre las iniciativas relacionadas con la sexualidad de 1985, 1989 y 1990 . En la Tabla 2 se muestran algunos temas que generaron antagonismo y opinión en la sociedad costarricense.

La educación media se convirtió en un espacio de disputa frente a los replanteamientos sobre nuevas masculinidades y feminidades; pero también hubo respuestas de sectores conservadores que apelaron a discursos basados en la normalización y el orden natural, como dispositivos de control y vigilancia, contra quienes se convierten en otredades. Y como lo escribe Bauman (2011), "Una vez despojado el otro de 'rostro', su debilidad invita a la violencia con naturalidad y sin esfuerzo" (p. 84). Una violencia manifiesta desde la cultura, lo simbólico y lo estructural para protegerse de quienes son vistas como personas extrañas y como amenazas del orden.

Así lo refleja una carta pública enviada por la Conferencia Episcopal de Costa Rica en relación con las Guías de Sexualidad Humana, en respuesta a un proceso de consulta iniciado por el Estado, en la cual se aduce que, aunque sus recomendaciones

Tabla 2. Representaciones simbólicas adjudicadas a hombres y mujeres

\begin{tabular}{|c|c|c|}
\hline Tema & Mujeres & Hombres \\
\hline La doble moral sexual & $\begin{array}{l}\text { Las mujeres que manifiesten } \\
\text { intereses y deseos sexuales } \\
\text { provocan el asedio de los } \\
\text { hombres. }\end{array}$ & $\begin{array}{l}\text { Las manifestaciones de } \\
\text { los varones son espera- } \\
\text { das, apoyadas y a menudo } \\
\text { gratificadas. }\end{array}$ \\
\hline Infidelidad & Inadmisible & Comprensible. \\
\hline Trabajo & $\begin{array}{l}\text { Es muy trabajadora en el } \\
\text { hogar, es una gran ama de } \\
\text { casa }\end{array}$ & $\begin{array}{l}\text { Si el marido participa, es } \\
\text { porque la mujer lo manda. }\end{array}$ \\
\hline Arte & $\begin{array}{l}\text { Mujer que baila clásico es } \\
\text { una baletista. }\end{array}$ & $\begin{array}{l}\text { Un hombre que baila es } \\
\text { afeminado. }\end{array}$ \\
\hline Conducta & Mujer delicada es fina. & Hombre delicado es marica. \\
\hline Estado civil & $\begin{array}{l}\text { Mujer soltera es una } \\
\text { frustrada. }\end{array}$ & $\begin{array}{l}\text { Hombre soltero es decidido } \\
\text { e independiente. }\end{array}$ \\
\hline
\end{tabular}

Nota: Elaboración propia a partir de información disponible en el Proyecto Educación en Población-Costa Rica-: Guía didáctica de sexualidad humana y vida familiar $9^{\circ} 1985$.

76 Sociedad y oficialismo: la crispación del discurso oficial sobre sexualidad del Ministerio de Educación Pública, Costa Rica, 1960-2011 Hermes Campos-Monge

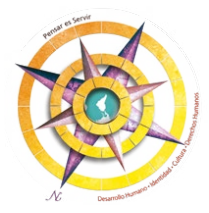


para adaptar los contenidos sobre sexualidad no son de carácter oficial, no existe otra opción viable que pueda brindar una educación para la sexualidad correcta como la establece la CECOR. Justamente porque estas políticas están pensadas para proteger los codiciados símbolos de la normalidad y a condicionar la conducta de los cuerpos. De acuerdo con la carta se establece:

Tres cosas con el mayor respeto queremos pedirle: a) Que el texto corregido de las Guía que hoy ponemos en sus manos sea el texto que en definitiva se adopte, publique y ponga en uso. b) Que sean en cada colegio, los profesores de Religión quienes debidamente preparados al efecto, impartan los cursos sobre sexualidad humana. c) Que se tome muy en cuenta a los padres de familia, principales responsables de la educación de sus hijos, a la hora de dar seguimiento y evaluar el desarrollo de los cursos. (Eco Católico, 1992).

La sexualidad y demás elementos asociados a ella, que son parte del proceso de vida y cotidianidad de los sujetos, representan el nacimiento de una tecnología de poder al servicio de la hegemonía que invade la vida privada y que es llamado por Foucault (citado por Daniel Toscano) el biopoder y lo define como:
El establecimiento, durante la edad clásica, de esa gran tecnología de doble faz — anatómica y biológica, individualmente y específicamente, vuelta hacia las relaciones del cuerpo y atenta a los procesos de vida-caracteriza un poder cuya más alta función no es matar sino invadir la vida eternamente. (Toscano López, 2008, p. 41)

El planteamiento sobre los contenidos de esta guía no dejó de ser un elemento de crispación y de control porque, aunque promoviera la participación de diferentes sectores sociales para que aportaran cómo se podría mejorar el programa, el MEP tenía completa libertad para decidir, como máxima entidad en educación, si valoraba o no la incorporación de esas apelaciones. "Es decir, son muchos y poderosos los constreñimientos y las influencias desde fuera del Estado, pero es en última instancia un grupo muy pequeño de personas en el Estado -a menudo una sola persona- quien decide lo que se hace o no" (Miliband, 1984, p. 126).

Para 1993 y 1999 el discurso contracultural continuó presente en los guías que el Ministerio de Educación Pública en conjunto con el Fondo de Población deseaba implementar en la instrucción costarricense. Sin embargo, la voluntad política no fue suficiente para la ejecución de esta guía; para lo cual se plantea dos posibles 
respuestas: Presiones muy fuertes de quienes por su posición de poder en la esfera social pueden generar un costo político, o por la falta de una política de Estado que le permitiera a todo el MEP poner en marcha a nivel país un programa sobre sexualidad.

No obstante, dentro de los programas oficiales del Ministerio de Educación prevalecía un antagonismo respecto a las Guías de la Sexualidad, ya que sus currículos privilegiaban la censura a nuevas masculinidades y feminidades, pues prevalecía un pensamiento que aduce a la idea de que solo existen dos sexos y dos géneros, provocando un sentido de exclusión para quienes no se encuentran en estos paradigmas. Así se narra en los siguientes objetivos:

Reconocer los cambios físicos en la adolescencia como un proceso de transición hacia la madurez, los acepto con naturalidad, ajustándome a ellos.

Valoro la importancia de practicar regularmente la higiene corporal para la conservación de la salud y la aceptación social.

Obtengo un concepto amplio y realista de lo que es la familia de acuerdo con la estructura, vínculos, autoridad y función que cumple en la sociedad. (MEP, 1990, pp. 15-17)
Este escenario continuó y se convirtió en una guerra ideológica que no resolvió ni logró atender el tema de la educación para la sexualidad. Las iniciativas planteadas fueron importantes como reseña histórica que se intentó llevar a cabo, pero la ausencia de una "política de Estado" no le permitió la trascendencia de este recurso a las aulas. No obstante, a finales de los noventa, nuevamente el Gobierno intenta desde el Despacho de la Primera Dama (Administración Rodríguez Echeverría 1998-2002) una iniciativa para capacitar a personal docente denominado Programa Amor Joven.

El Programa Amor Joven, aprobado en 1998, fue un instrumento elaborado para capacitar al personal docente a través de pilotajes; "esto significa que se seleccionarían zonas con mayor vulnerabilidad considerando criterios como embarazo adolescente y prevención del abuso sexual" (Comunicación personal, Cartín, 2019). No obstante, fue altamente cuestionado por sectores sociales como la jerarquía de la Iglesia Católica que, de acuerdo con una declaración para el periódico La Nación, argumentó:

...esos planes solo tienden a buscar el libertinaje de los jóvenes, desorientados y estimular las conductas de homosexualismo y lesbianismo. Además promueve el uso indiscriminado de

78 Sociedad y oficialismo: la crispación del discurso oficial sobre sexualidad del Ministerio de Educación Pública, Costa Rica, 1960-2011

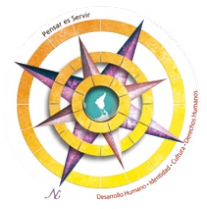


anticonceptivos, reduce la dignidad del ser humano con versiones materialistas y promueve la sexualidad abierta, cuya consecuencia es más embarazos en madres solteras. (Mora, 1999, p. 16A)

Las afirmaciones de la Iglesia parecen estar muy conectadas con el contexto internacional sobre las ideas contraculturales que plantearon los movimientos feministas y los movimientos homosexuales durante los años setenta y con mayor fuerza en los ochenta. No obstante, esto solo fue una excusa ideológica, porque la realidad social y la necesidad de implementar un programa sobre sexualidad era indispensable, porque, según datos del Registro en 1999, "más de 15 mil adolescentes quedan embarazadas cada año" (Cantero, 1999, p. 7).

La población adolescente fue la principal víctima de la ausencia de una política y un programa sobre sexualidad, que la orientara sobre el empoderamiento de sus cuerpos y la toma de decisiones responsables a partir de conocimiento científico. Esto implicaba el empleo del condón, maternidades deseadas, paternidad responsable (los hombres deben aprender a ser padres y no solo un rol proveedores) y la visibilización de las nuevas identidades de género, así como una nueva lectura sobre la construcción de masculinidades y feminidades.
Las cifras anuales de embarazo adolescente y la preocupación de dar una respuesta oportuna, provocó que el 12 de junio del 2001, "el Consejo Superior de Educación aprobara la Política de Educación Integral de la Expresión de la Sexualidad Humana" (Báez, 2001). Un instrumento que le permitiría al MEP desarrollar una estrategia con carácter ministerial sobre el país para abordar la sexualidad.

La política está basada en varios principios rectores de los cuales se analizarán los más importantes, en relación con los objetivos de la investigación. Este documento establece que: "la educación de la sexualidad humana es un derecho y un deber primario de los padres y madres de familia; los centros educativos, por su parte, tiene la insoslayable obligación de atender esa educación subsidiaria" (MEP, 2001, p. 5). Los discursos basados en control y poder pueden representar un peligro inminente, en la medida en que los "otros" son vistos como objetos dominados desde los espacios de privilegio. Sobre esto, advierte Bauman (2011), que todo lo que esta fuera del control del Estado, es una amenaza porque "uno nunca sabe dónde y cuándo se harán carne las palabras de advertencia” (p. 80).

Otro de los elementos que ponen de manifiesto una preocupación sobre 
el programa de sexualidad es la forma en la que se integra al currículo educativo:

La misma debe ser considerada transversalmente en el currículo escolar de la forma que supere los enfoques parciales en los que se propone como una materia más, $\mathrm{o}$ la visión horizontal que la concibe como un componente más de diferentes asignaturas. Esta transversalidad implica integrar al currículo establecido su abordaje, en todos los niveles y modalidades del sistema educativo. (MEP, 2001, p. 5)

La trasversalidad tiene varios problemas que parecen ser una constante para enseñar sobre sexualidad en Costa Rica. Es necesario crear una materia, porque la transversalidad no garantiza que docentes enseñen a estudiantes, porque está sujeto a la disposición, disponibilidad y tiempo en sus materias. Este tipo de acciones pone en duda las intenciones reales de crear una política que no es clara y con debilidades muy fuertes, si se considera la experiencia previa adquirida del país en esta temática (Comunicación personal, Sevilla y Campos, 2019).

La esperada política sobre sexualidad, según Cartín, fue elaborada en consenso con la jerarquía de la
Iglesia Católica, debido a la "cercanía que mantenía el ministro de la época Guillermo Vargas con el OPUS DEI". De acuerdo con Alvarenga (2012), "quienes colaboran desde distintos ámbitos en la construcción de la moral, se abocan a fijar los límites de lo aceptable y lo indeseado" (p. 56). No obstante, durante el proceso de búsqueda de fuentes documentales, no fue posible encontrar evidencia directa del alegato de Cartín, sobre las relaciones del ministro de Educación con esta organización. Sin embargo, la conceptualización de la sexualidad, plasmada en la política, induce a pensar que pudo existir esa vinculación. La política define la sexualidad como:

...un bien: parte del don que Dios vio que "era muy bueno" cuando creó la persona humana a su imagen y semejanza, y "hombre y mujer los creó". En cuanto modalidad de relacionarse y abrirse a los otros, la sexualidad tiene como fin intrínseco el amor, más precisamente el amor como donación y acogida, como dar y recibir. (Alvarenga, 2012, p. 56)

Existe una inquietante necesidad de entender la sexualidad desde un enfoque heterosexual; pero estableciendo los límites entre hombres y mujeres, definiendo sus alcances y

80 Sociedad y oficialismo: la crispación del discurso oficial sobre sexualidad del Ministerio de Educación Pública, Costa Rica, 1960-2011

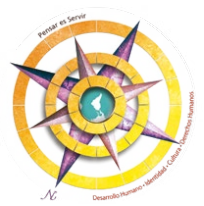


cualidades esperadas, como lo describe Ann Fausto (2006):

Con las prisas y la emoción de la partida hacia los Juegos Olímpicos de 1998, María Patiño, la mejor vallista española, olvidó el prescriptivo certificado médico que debía dejar constancia, para la seguridad de las autoridades olímpicas, de lo que parecía más que obvio para cualquiera que la viese: que parecía mujer. (p. 15)

Las políticas de la identidad son un constante en la educación costarricense, la imperiosa necesidad de privilegiar el sistema sexo-género como únicas expresiones del orden natural, nuevamente coloca a la educación costarricense en una disputa ideológica y como lo escribe Bauman (2011):

En un mundo inseguro, seguridad es el nombre del juego. En un mundo tan inseguro como el nuestro es preciso recortar o suspender la libertad personal de la palabra y acción, el derecho a la privacidad, el acceso a la verdad: todo lo que solíamos asociar a la democracia y en cuyo nombre todavía vamos a la guerra. (p. 33).

El conocimiento sigue estando vinculado a los estratos de poder y narradas desde los espacios del disciplinamiento. La educación no puede ser en ninguna medida un instrumento de opresión, sino de liberación. Sin embargo, esto es solo un idilio y evoca a plantearse ¿Qué es la verdad? y ¿Quién tiene la verdad? "La verdad es un constructo amparado por los intereses del control mismo, legitimado por las estructuras de poder que determinar qué y cómo se debe de saber" (Castro, 2016, p. 52); entonces no hay un proceso liberador sino algo que se quiere mostrar como verdadero.

Para inicios del 2011, la relación costo político sobre el contexto nacional, permitió que se creara el Programa de Educación para la Afectividad y Sexualidad Integral, dentro de la materia de ciencias del tercer ciclo; aunque lo más sensato era crear una materia específica, si ya se contaba los insumos suficientes para hacerlo. Pero de acuerdo con Sevilla y Campos (Comunicación personal, 2019), no fue así:

...se incorporó fue en la materia de ciencias, ¿por qué en ciencias? Por qué en ese momento era la que cubría el área de los estudiantes, la materia o la asignatura que cubría el área de los estudiantes que era como con más problemática, que se estaba presentando más embarazos, más violencia en esa etapa etárea, en ese grupo de estudiantes. Entonces fue ahí ¿Dónde, en qué materia tenía que ser? 
¿Dónde lo incorporábamos? Estaban los compañeros de orientación, pero ellos no cubrían todo el grupo de estudiantes del país. Entonces ciencias si tenía unas áreas muy afines, cómo cuando se daba el sistema reproductor, que [sic] aunque era muy temático, pero que era donde podía incorporarse esta área de afectividad y sexualidad, por eso ahí se pensó que tenía que entrar en Tercer Ciclo en Ciencias.

El Programa de Educación para la Afectividad y Sexualidad Integral que se enmarca dentro a la política del 2001, deja en evidencia dos aspectos: es una política que se establece solo como un mecanismo legitimador para que sea posible desarrollar acciones estructuradas sobre sexualidad y, en otro sentido, se continua con un juego político de poderes entre el Estado y los sectores sociales conservadores como la Iglesia Católica, donde la educación se convierte en un espacio de disensión. Este juego político, plantea Miliband (1984), "depende sobre todo de la medida en que las presiones desafíen la hegemonía de la clase dominante en dicha sociedad" (p. 127).

Se debe rescatar que los contenidos del programa PASI (Programa de Educación para la Afectividad y Sexualidad Integral) aborda temáticas asociadas a la vulnerabilidad, respeto por la opinión distinta, conductas de riesgo (alcoholismo, drogas, pornografía y abuso sexual), paternidad y maternidad responsables, infecciones de transmisión sexual, el placer y el deseo etc. Cada uno de los temas mencionados no está alejado de la realidad social costarricense, algunos también se asocian a conductas basadas en el poder como el caso del abuso sexual; otras son catalogadas como anormales como la pornografía, porque se interpreta el sexo en sí mismo como algo restrictivo y perverso, porque ver pornografía implica poseer un comportamiento no esperado y mal visto.

La sexualidad siempre será un espacio de disputa por el control de los cuerpos, donde se mantenga y reproduzca el régimen de normatividad y normalidad corporal, "donde la dicotomía cultura-naturaleza se reproduce en masculino-femenino, siendo este último particularmente vinculado a elementos naturalizados $\mathrm{y}$ esenciales mientras lo masculino se asocia a lo neutral y universal" (Amigot Leache y Pujal i Lombart, 2009, p. 123).

No hay forma de escapar de un sistema perverso ante la incertidumbre de encontrar la verdad dentro de la verdad. La necesidad de dominar las conductas cotidianas se ha

82 Sociedad y oficialismo: la crispación del discurso oficial sobre sexualidad del Ministerio de Educación Pública, Costa Rica, 1960-2011

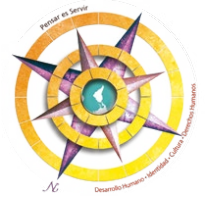


convertido en instrumentos de discusión política, una verdadera invasión a la privacidad y un asalto a la democracia, porque la posibilidad de ser, está limitada a los controles institucionales y culturales.

\section{Algunas reflexiones}

La sexualidad es un espacio de disputa por el control y subordinación de los cuerpos; pero, al mismo tiempo, es un poder que depende de la voluntad y la docilidad para ser objeto de ese poder, pues la resistencia es una alternativa que desestabiliza un sistema perverso que intenta mantener el orden hegemónico.

La necesidad de dominar las conductas cotidianas se ha convertido en instrumento de discusión política, una verdadera invasión a la privacidad y un asalto a la democracia, porque la posibilidad de ser está limitada a los controles institucionales y culturales, que regulan y establecen mediante códigos de normalidad y normativismo, la forma en la que deben comportarse hombres y mujeres.

\section{Referencias}

Alvarenga, P. (2012). Identidades en disputa: Las reivindicaciones del género y de la sexualidad en la Costa Rica de la primera mitad del siglo XX. Editorial UCR.

Amigot Leache, P. y Pujal i Lombart, M. (2009). Una lectura del género como dispositivo de poder. Revista Sociológica, 70. http://www.sociologicamexico.azc.uam.mx/index.php/ Sociologica/article/view/145/136

Angulo, Y. (01 de junio 2019). No queremos otro activista como Ministro de Educación, señala Nueva República. Elmundo. https://www.elmundo.cr/costa-rica/ no-queremos-otro-activista-como-ministro-de-educacion-senala-nueva-republica/

Arroyo Navarrete, L. (2008). El derecho a la educación integral para la sexualidad y las y los adolescentes en Costa Rica desde la perspectiva de género [Tesis de Licenciatura en Derecho]. Universidad de Costa Rica. http://iij.ucr.ac.cr/wp-content/uploads/ bsk-pdf-manager/2017/07/El-Derecho-a-la-Educaci\%C3\%B3n-Integral-para-la-Sexualidad-de-las-y-los-Adolescentes-en-Costa-Rica-desde-la-Perspectiva-de-G\%C3\% A9nero.pdf

Avendaño, C. (22 de diciembre 2003). Educación sexual integral: Una urgente necesidad. $E l$ Heraldo de la Nueva Era, p.14.

Bauman, Z. (2011). Daños colaterales: Desigualdades en la era global. Editorial Impresora y Encuadernadora Progreso. 
Bloch, Vital H. (julio-diciembre 2013). Betty Friedan: El trabajo de las mujeres, el liberalismo posterior a la Segunda Guerra Mundial y los orígenes del liberalismo femenil en Estados Unidos. Revista Signos Históricos, 30. http://www.redalyc.org/pdf/344/34428955003. pdf

Bottticelli, S. (agosto-octubre 2015). La gubernamentalidad del Estado en Foucault: Un problema moderno. Revista Praxis Filosófica, 42.

Bourdieu, P. (2000). La dominación masculina. Editorial Anargrama.

Brenes Camacho, G. (2014). Describiendo procesos históricos de "baby boom" durante mediados del siglo XX en tres nacionales latinoamericanas usando estudios de envejecimiento, en: Propuesta de trabajo en el VI Congreso de la Asociación Latinoamericana de Población (Centro Centroamericano de Población y Escuela de Estadística, Universidad de Costa Rica). http://www.alapop.org/Congreso2014/DOCSFINAIS_PDF/ ALAP_2014_FINAL96.pdf

Cantero, M. (29 de octubre 1999). Educación sexual sin dar frutos. La República, p. 7.

Cartín, T. (2019). Breve cronología de la educación de la sexualidad en Costa Rica. MEP.

Castillo, J. P. (8 de abril 2001). Comienza la distribución de guía sexual. Eco Católico, p. 10.

Castro, E. (julio 2016). La verdad del poder y el poder de la verdad en los discursos de Michael Foucault. Revista Tópicos, 31.

Centro Feminista de Información y Acción. (s. f.). Sobre CEFEMINA. https://www.cefemina. com/Nueva/

Chacón Román, M. (26 de octubre 1999). Acuerdo sobre la educación sexual. Al Día, p. 3.

Conde Soto, F. (marzo-octubre 2017). El cuerpo más allá del organismo: El estatus del cuerpo en el psicoanálisis lacaniano. Revista Internacional de Filosofía Contrastes, 2.

Conferencia Episcopal de Costa Rica. (2001). Educación en la sexualidad: Guía para padres de familia y educadores. CONEC.

Díaz, M. (mayo-septiembre 2013). Del disciplinamiento de los cuerpos al gerenciamiento de la vida. Mutaciones biopolíticas en el presente en torno a la construcción de la anormalidad. Revista de Prácticas y Discursos, 2. http://biblioteca.clacso.edu.ar/Argentina/ ces-unne/20141001053149/Diaz.pdf

Eco Católico. (09 de agosto 1992). Guías de sexualidad humana. Eco, p. 2.

Eco Católico. (16 de agosto 1992). Carta de presentación al señor Ministro de Educación, de la respuesta de la Conferencia Episcopal a la consulta sobre las Guías Didácticas de Sexualidad. Eco, p. 2.

Facio, A. y Fries, L. (2005). Feminismo, género y patriarcado. Revista sobre Enseñanza del Derecho de Buenos Aires, 3(6). http://www.derecho.uba.ar/publicaciones/rev_academia/ revistas/06/feminismo-genero-y-patriarcado.pdf

Fausto-Sterling, A. (2006). Cuerpos sexuados: La política de género y la construcción de la sexualidad. Melusina.

Foucault, M. (2003). Disciplina: Los cuerpos dóciles. En Vigilar y castigar nacimiento de la prisión. Siglo Veintiuno Ediciones Argentina.

84 Sociedad y oficialismo: la crispación del discurso oficial sobre sexualidad del Ministerio de Educación Pública, Costa Rica, 1960-2011 Hermes Campos-Monge

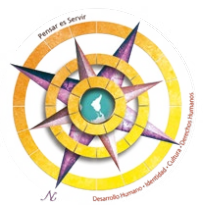


Freire, P. (1993). Pedagogía de la esperanza: Un reencuentro con la pedagogía del oprimido. Editorial Siglo XXI. http://enlaceacademico.ucr.ac.cr/sites/default/files/publicaciones/ PEDAGOG\%C3\%8DA\%20DE\%20LA\%20ESPERANZA-FREIRE.pdf

La Nación. (17 de marzo 1974). Educación sexual basada en una concepción materialista. La Nación, p. 8.

La Nación. (19 de agosto 1971). Inaugurando seminario de educación sexual para auxiliares de orientación. La Nación, p. 47.

La Nación. (20 de marzo 1974). Educación sexual: Limpia su trayectoria y cristianos todos sus fundamentos. La Nación, p. 32.

Lorite Mena, J. (1995). Sociedades sin Estado. El pensamiento de los otros. Ediciones Akal.

Malavassi, G. (28 de febrero 1979). El problema sexual. La Nación, p. 15.

Miliband, R. (enero-marzo 1984). Poder estatal e intereses de clase. Revista Zona Abierta. 30.

Ministerio de Educación Pública. (1964). Memoria Anual 1963. MEP. https://mep.janium.net/ janium-bin/pdfview.pl?Id=20200429124249\&r=170804\&t=p

Ministerio de Educación Pública. (1985). Guía Didáctica en Sexualidad y Vida Familiar $9^{\circ}$ Tercer Ciclo. FNUAP-MEP-UNESCO.

Ministerio de Educación Pública. (2001). Política de Educación Integral de la Expresión de la sexualidad Humana. Autor.

Ministerio de Educación Pública. (1965). Programa de Educación para el Hogar, Tercer Ciclo. MEP.

Ministerio de Educación Pública. (1979). Programa de Ciencias Generales, Tercer Ciclo. MEP.

Ministerio de Educación Pública. (1985). Proyecto Educación en Población -Costa Rica-: Guía didáctica de sexualidad humana y vida familiar $7^{\circ}$. Imprenta Nacional.

Ministerio de Educación Pública. (1989). Proyecto de Educación en Población -Costa Rica- Guía didáctica de Sexualidad Humana y Vida Familiar $7^{\circ}$ Tercer Ciclo. FNUAP-MEP-UNESCO

Ministerio de Educación Pública. (1990). Programa de Educación para el Hogar Tercer Ciclo. Imprenta Nacional.

Ministerio de Educación Pública. (1993) Proyecto Educación en Población-Costa Rica- Guía Didáctica de Sexualidad Humana $9^{\circ}$. MEP-UNESCO.

Ministerio de Educación Pública. (1999) Manual didáctico de sexualidad humana $8^{\circ}$ Tercer Ciclo. MEP.

Ministerio de Educación Pública. (2012). Programa de Enseñanza de las Ciencias: Programa de Afectividad y Sexualidad Integral Tercer Ciclo. MEP.

Molina Jiménez, I. (2019). Deliciosas tempestades. Las mujeres y la educación sexual en Costa Rica entre 1920 y 1960. Revista Descentrada, 3(1). http://www.memoria.fahce.unlp. edu.ar/art_revistas/pr.9641/pr.9641.pdf

Monestel Arce, Y. (10 de mayo de 1960). La educación sexual y el Estado. La Prensa Libre, p. 2 . 
Mora, E. (6 de septiembre 1999). Obispos cuestionan los programas sexuales. La Nación, p. 16.

Oficina de la Primera Dama, Consejo Interinstitucional de Atención a la Madre Adolescente, Instituto Nacional de las Mujeres. (1999). Amor joven y construyendo oportunidades. Imprenta Nacional.

Osorio, J. (2012). Estado, biopoder y exclusión: Análisis de la lógica del capital. Editorial Anthropos.

Picado Gatjens, M. (2006). Sexualidad y catolicismo. Editorial Lara Segura.

Poder Judicial de Costa Rica, Sala Constitucional: sentencia 16583-15

Preciado, B. (2002). Manifiesto contrasexual: Prácticas subversivas de identidad sexual. Editorial Opera Prima.

Ranucci, T. (30 de mayo 1959). Educación sexual y coeducación. La República, p. 20.

Sáenz Valverde, G. (29 de agosto 2000). A los adolescentes hay que hablarles claro sobre sexo. Diario Extra, p. 6.

Sánchez Amaya, T. (2013). La evaluación educativa como dispositivo de constitución de sujetos. Revista Latinoamericana de Ciencias Sociales, Niñez y Juventud, 11 (2), 756. http:// www.scielo.org.co/pdf/rlcs/v11n2/v11n2a21.pdf

Schifter Sikora, J. (1989). La formación de una contracultura: Homosexualismo y SIDA en Costa Rica. Ediciones Guayacán.

Toscano López, D. (2008). El bio-poder en Michael Foucault. Revista Universitas Philosophi$c a, 25(51)$.

Valerio Charpentier, E. (1993). Marina Peralta Villalobos, Guía Didáctica de Educación en Población $7^{\circ}$ Tercer Ciclo. MEP-UNESCO.

van Dijk, T. A. (septiembre-octubre 1999). El análisis crítico del discurso. Revista Anthropos. http://www.discursos.org/oldarticles/El\%20an\%E1lisis\%20cr\%EDtico\%20del\%20discurso.pdf

Vio Hernández, F. (14 de diciembre 2000) La Iglesia desaprobó los programas “Amor Joven” y "Construyendo oportunidades". La Prensa Libre, p. 12

Wittig, M. (2006). El pensamiento heterosexual y otros ensayos. Editorial EGALES.

Zúñiga Ureña, L. (23 de octubre 2003) Defensoría externó su preocupación por el índice de embarazos en adolescentes. La Prensa Libre, p. 5.

Zúñiga Ureña, L. (23 de octubre 2003). Programas educativos deberán ahondar en educación sexual. La Prensa Libre, p. 5.

Zúñiga Ureña, L. (23 de octubre 2003). Reconocen vacío en materia de sexualidad. La Prensa Libre, p. 2.

86 Sociedad y oficialismo: la crispación del discurso oficial sobre sexualidad del Ministerio de Educación Pública, Costa Rica, 1960-2011 Hermes Campos-Monge

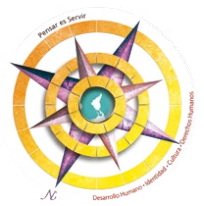

